\title{
La doble normatividad de la Constitución de 1978: la Transición como momento evolutivo del ser social español ${ }^{1}$
}

\section{The Double Normativity of the Constitution of 1978: the Transition as an Evolutionary Moment of the Spanish Social Being}

\author{
Eloy García ${ }^{2}$ \\ Universidad Complutense de Madrid (España)
}

Recibido: 13-06-2021

Aceptado: 19-06-2021

\section{Resumen}

En el presente artículo se plantea una crítica a la tesis que define la Transición política española como un exitoso intento de poner punto final a la "ley del péndulo" que había venido rigiendo nuestra historia constitucional. Por un lado, esta tesis minusvalora las condiciones de la situación española de 1978, marcada por el tránsito entre dos mundos, el moderno que heredaba y el emergente postmoderno, que se convertiría en una realidad incuestionable a partir de 1989. Además, la Constitución española de 1978 se redactó en un momento en que estaban declinando los supuestos conceptuales político-normativos del paradigma constitucional dominante en Europa tras la Segunda Guerra Mundial. Asimismo,

\footnotetext{
${ }^{1}$ Este Trabajo es resultado del proyecto de investigación financiado por el Ministerio de Ciencia, Innovación y Universidades RTI2018-096103-B-100 “Enseñar la Constitución. Educar en Democracia", aprobado en la Convocatoria I+D+i "Retos de investigación" correspondiente a 2018.

2 (eloygarc@gmail.com) Catedrático de Derecho Constitucional de la Universidad Complutense de Madrid. Fue Catedrático en la Universidad de Vigo y es Técnico de la Administración Civil en excedencia. Ha sido Profesor Titular de la Universidad de Alcalá y de la Universidad Complutense. En ellas, fue Vicedecano de la Facultad de Derecho. Ha sido Profesor Invitado en prestigiosas Universidades internacionales, como París, Bolonia, Coimbra, Westminster y Turín, entre otras. Es autor de numerosas obras de Derecho Constitucional y Administrativo. Es Director de la colección Clásicos del Pensamiento, de la editorial Tecnos. Entre sus últimas publicaciones: Weimar, el 'Momento democrático de los modernos' entre dos otoños revolucionarios: noviembre 1919 y noviembre 1989 (CEPC, 2021); "El rey en la Constitución de 1978: el cometido de la Monarquía en una democracia con pretensión de veracidad” (Revista de Derecho Político, 2019); “¿Es constitucional prohibir la reelegibilidad del Presidente del gobierno para un tercer mandato?” (Teoría y Realidad Constitucional, 2018).
} 
la tesis ignora el rasgo específico diferencial español: la guerra civil de 1936-1939 y la subsiguiente ruptura y separación radical de la modernidad española en dos tramos históricos distintos: uno iniciado con la Revolución Francesa y culminado en la más absoluta destrucción del orden político y social preexistente; y otro que arranca en 1939, desde la (re)construcción de cero de un patrón de sociedad y una cultura radicalmente nuevos, con los que se toparon los españoles en diciembre de 1975 cuando asumieron su pleno protagonismo político en una situación inédita y carente por completo de precedentes en nuestra tradición constitucional nacional.

Palabras-clave: Transición política española, Sociedad española, Poder constituyente evolutivo

\begin{abstract}
In this article there is a criticism of the thesis that defines the Spanish political transition as a successful attempt to put an end to the "law of the pendulum" that had been governing our constitutional history. On the one hand, this thesis underestimates the conditions of the Spanish situation of 1978, marked by the transit between two worlds, the modern one that inherited and the emerging postmodern, which would become an unquestionable reality from 1989. In addition, the Spanish Constitution of 1978 was drafted at a time when the political-normative conceptual assumptions of the dominant constitutional paradigm in Europe after World War II were declining. Likewise, the thesis ignores the specific spanish differential feature: the civil war of 1936-1939 and the subsequent rupture and radical separation of Spanish modernity into two distinct historical sections: one initiated with the French Revolution and culminated in the most absolute destruction of the pre-existing political and social order; and another that starts in 1939, since the (re)construction of zero of a radically new pattern of society and culture, with which the Spaniards encountered in December 1975 when they assumed their full political protagonism in a situation unprecedented and completely devoid of precedents in our national constitutional tradition.
\end{abstract}

Keywords: Spanish political transition, Spanish society, Evolutionary constituent power.

\title{
Presentación de la hipótesis de trabajo
}

Ha sido lugar común admitido por los estudiosos definir la Transición política española como un exitoso intento de poner definitivo punto final a la "ley del péndulo" que tradicionalmente había venido rigiendo nuestra historia 
constitucional desde sus orígenes en la norma gaditana de 1812. La tesis, sugerida de tiempo atrás, entre otros por Sánchez Agesta, explica que la historia hispana del XIX y primera parte del XX, había estado presidida de modo ininterrumpido por una sucesión alternativa de constituciones, en la que a un texto progresista le seguía automáticamente otro de signo conservador que, a su vez, resultaba reemplazado por otro nuevo de carácter progresista, y así repetidamente hasta terminar desembocando en la Guerra Civil. De manera que todas nuestras constituciones históricas habrían sido indefectiblemente textos de partido, excluyentes de la opción adversaria, que para conseguir plasmar sus proyectos y obtener espacios capaces de albergar sus pretensiones políticas no encontraron mejor posibilidad que romper violentamente el orden constitucional que las negaba y al que, llegada su oportunidad, ellas también negarían. Del mismo diagnóstico participarán sustancialmente los libros de Tomás Villarroya y Solé Turá que, desde posicionamientos diferentes, en el instante de la elaboración de la Constitución de 1978, iban a contribuir a la formación de la opinión doctrinal que aspiraba a convertir el texto nacido de la Transición en un instrumento forjado en un enorme consenso político e ideológico abierto al desarrollo de alternativas discrepantes, y encaminado a operar como "ley de hierro jurídica" destinada a estabilizar la democracia pluralista en la vida española. La juridicidad de la Constitución y el papel atribuido al Tribunal Constitucional serían dos piezas medulares para la consecución de semejante remedio, en la medida que desde el carácter dirigente de una Constitución autoproclamada derecho directamente aplicable garantizaban la férrea conducción de los acontecimientos por el camino democrático estipulado en la Ley Fundamental. Y esta ha sido la premisa que hasta fechas recientes ha servido para conformar la lectura de la Constitución de quienes cifran en su normatividad y en el estricto cumplimiento de sus preceptos el mecanismo adecuado para la realización de nuestras diferencias democráticas en pacífica alternancia política.

Pero a pesar de la generalizada aceptación que todavía mantiene entre la doctrina, la tesis ofrece importantes debilidades argumentales que dan pie a considerables dudas y suscitan notables reparos en relación con el tipo de cultura política que surgió de la Transición y de la que -conviene no olvidarlotambién se nutrieron los contenidos de la normatividad que informó nuestra Constitución:

- Ante todo, porque se trata de una tesis acusadamente ahistórica y no tanto porque interprete correcta o incorrectamente el pasado, sino porque desconoce $\mathrm{y}$, en cualquier caso, minusvalora manifiestamente las condiciones del presente en que, desde una perspectiva global, se encontraba inmersa la circunstancia española de 1978, marcada 
por el tránsito entre dos mundos, el moderno que heredaba y en el que España todavía parecía aparentemente hallarse sumida, y el emergente postmoderno que paulatinamente se iría abriendo paso y haciendo más patente, y que se convertiría en una realidad tangible incuestionable a partir de 1989.

- Dicho de otro modo, a diferencia de lo acaecido un poco antes en Portugal, donde la Revolución -la última revolución moderna- abrió camino a una tardía pero plena integración de la nación lusa en el ciclo de las Constituciones normativas que desde la II a Guerra Mundial se habían impuesto en el continente europeo, España llegaba a la democracia en un momento en que empezaban a apreciarse síntomas claros de agotamiento del ciclo del mundo moderno y de su sustitución por otras realidades políticas, sociales e intelectuales postmodernas que la nueva Constitución de 1978 no podía permitirse ignorar si se esforzaba en mantenerse tan apegada a la realidad de su época como efectivamente lo estuvo. Un dato que en última instancia acabó siendo la clave y el gran secreto que la impulsó y a la postre la hizo posible.

- Por otro lado, y consecuencia necesariamente derivada de lo anterior, la Constitución española de 1978 se redactó en un momento en que estaban declinando los supuestos conceptuales político-normativos que integraban el paradigma constitucional que se había impuesto en Europa tras la Segunda Guerra Mundial, porque respondían a un Tiempo que también estaba declinando. Algo que, sin ir más lejos, se apreciaba de manera clamorosa en instituciones tan cruciales para la democracia como los partidos de masas, aquejados de una suerte de aluminosis intelectual imputable a una disolución de las ideologías a la que desde los años setenta se venía refiriendo insistentemente Judith Shklar, o en la transformación experimentada en los derechos por razón a la redefinición acusadamente individualista de una libertad reenfocada a la procura de la emancipación del hombre de su condición de ser social y no a su ejercicio en el orden colectivo, o en la crisis experimentada por el Derecho como disciplina dirigente, que se demostraba cada vez más incapaz de imponerse a una vida social que ya no parecía dominar (Luhmann).

- Pero, además, la tesis no sólo era ahistórica porque desconociera la realidad coetánea y pretendiera convertir un desiderátum en voluntad jurídica; lo era también porque ignoraba el rasgo específico diferencial que había marcado a hierro y fuego la existencia española: la guerra civil de 1936-1939 y la subsiguiente ruptura y separación radical de la modernidad española en dos tramos históricos distintos emplazados en solución de continuidad interna. Uno, ya concluido de 
manera definitiva, que se había iniciado con la Revolución Francesa y que había culminado en la más absoluta destrucción y práctica aniquilación del orden político y -lo que a nuestros efectos parece más trascendente- social preexistente; y otro segundo, de diferente cuño, que había arrancado en 1939, desde la (re)construcción de cero por el poder militar triunfante, de un patrón de sociedad y una cultura radicalmente nuevos, con los que se toparon súbitamente los españoles en diciembre de 1975 cuando, huérfanos del dictador, asumieron su pleno protagonismo político en una situación absolutamente inédita y carente por completo de precedentes en nuestra tradición constitucional nacional.

- Así pues, todo indica que la historia española del XIX fue una historia de desequilibrios y de repetidos golpes de mano constitucionales, muy similar y sin diferencias sustanciales con lo acontecido en el continente europeo, que alcanzó la estabilidad cuando se llegó a la recasting a que se refiere Arno Mayer en su conocido libro $L a$ persistencia del Antiguo Régimen. Estabilidad que en el caso español saltaría hecha pedazos con el cataclismo que engendró la guerra civil, dando paso a otra realidad de raíz nueva y privativa del ser nacional que llegaría y se extendería hasta el momento actual, y de la que era imposible prescindir en 1975 para idear cualquier proyecto constitucional de futuro, salvo si se aspiraba a emprender una nueva revolución, posibilidad inimaginable a aquellas alturas del mundo y de la sociedad.

A pesar de lo obvio que pueda parecer hoy todo esto, y de lo indiscutible que resulte la necesidad de admitir el peso y la presencia de estos datos en nuestra Transición política, lo cierto es que no influyeron de manera relevante en la formación de la conciencia que inspiró a la intelligentzia española de la época que, más que preocupada por construir una identidad constitucional nacional a la altura de los tiempos, se esforzó cuanto pudo en asumir como propia la misma auto-comprensión que había permitido a Europa establecer la democracia después de 1945, en el convencimiento de que, de este modo, sería posible superar aquella negación crónica entre opciones políticas adversarias de la que se derivaba nuestra inestabilidad constitucional, y que en 1977 era considerado como el gran problema histórico a afrontar. Lo que no quiere decir que como hechos fácticos no incidieran claramente en el proceso real -en la "verità effettuale della cosa"- que condujo a la Constitución democrática, sino que la reflexión sobre esos datos fácticos no formó parte de la conciencia explícita que guio el quehacer de la élite intelectual y jurídica española que asumió el poder con la Transición. Lo que naturalmente implicó que tales 
hechos quedasen sepultados y olvidados por otros hechos posteriores, una vez se hubo alcanzado el objetivo de convertir la Constitución en punto de arranque de una democracia que se auguraba felizmente estabilizada por un derecho marcadamente dirigente y, mucho más, una vez se llegó a consumar la añorada integración de España en la que luego sería Unión Europea. Sólo treinta y cinco años después, cuando de pronto los acontecimientos volvieron a arrojar nubes negras y cuajadas de problemas sin respuesta y comenzaron a soplar otra vez inquietantes vientos de crisis en la sociedad, reapareció entre los autores la preocupación por la interpretación de los acontecimientos del pasado, en el deseo - para unos- de buscar responsabilidades por lo que estaba sucediendo en los restos autoritarios de un franquismo que, a su entender, permanecía emboscado entre los cimientos de una democracia que no era lo que su nombre indicaba; y, para otros, más asépticos y objetivos, en el propósito de hallar soluciones a los desafíos del momento desde la comprensión de los factores fundacionales que habían construido el Estado Constitucional en la convicción de que -como enseñaban los clásicos, empezando por Maquiavelo- en el conocimiento de los orígenes de los Estados residen siempre las claves que permiten regenerar la política y volver a recuperar los principios ("ridurre ai principi").

Evidentemente, no es posible detenerse aquí a efectuar ahora un repaso pormenorizado de todas y cada una de estas cuestiones. Si se alude a ellas es para encadenar de forma que no deje lugar a dudas los eslabones que soportan la hipótesis de trabajo que defiende este ensayo. Y esta hipótesis afirma sencillamente que la Constitución de 1978 nació de una transformación evolutiva del ciclo español iniciado en 1939, y se insertó en un marco decididamente postmoderno para el que la política era notoriamente secundaria respecto de una realidad y una estructura social que atendía - y todavía atiende- a fundamentos operativos funcionales, y en cierta manera coyunturales, que venían construidos como hechos y no como principios. Ese es el motivo por el que, desde los primeros tiempos, nuestra existencia democrática se organizó justamente en un entendimiento desustanciado de la política, que desde entonces se ha movido en la confluencia de dos grandes vectores operativos: primero, y desde la lógica constitucional, el que marca el imparable predominio de una hiperrealidad institucional, que bajo la forma de "Democracia simulativa" (Blühdorn) tiende a presentar como verdad política lo que sólo es un espejismo virtual construido a manera de Fantasía y en la más pura ensoñación tecnológica. Segundo, y desde la óptica de la sociedad, una existencia crecientemente desintegrada y cada vez más articulada y nucleada en torno a grupos de interés que actúan presionando sobre las frágiles instituciones del Estado de cara a la consecución de sus objetivos parciales y particulares, sin ningún escrúpulo ni el menor rastro de conciencia colectiva como totalidad nacional. 
Para desarrollar cabalmente está afirmación, conviene organizar nuestro trabajo en tres apartados desde el objetivo de conformar cada uno de ellos como un eslabón independiente y racionalmente interconectado con la hipótesis central en que descansa toda la argumentación, a saber: que la crisis de lo constitucional en España es lisa y llanamente una crisis de la postmodernidad y no de la persistencia actual del franquismo político.

1. La guerra civil supuso una ruptura radical con el curso natural de la historia española y trajo una etapa nueva y sin precedentes, construida a modo de tabula rasa desde un modelo de sociedad estructurada funcionalmente como mera agrupación de individuos y de la que estaba totalmente ausente la política, y a la que únicamente preocupaba alcanzar cierto grado de bienestar personal y asegurarse su disfrute sin inquietudes. El poder político concebido como un poder de facto y ajeno a la sociedad, estuvo residenciado sin reservas durante casi cuarenta años (1939-1975) en las solas manos del jefe de un ejército colonial forjado en los más acendrados postulados anti-ideológicos del militarismo.

2. La Transición implicó un punto y seguido en la evolución de la sociedad nacida del proceso de construcción ex novo que siguió a la Guerra Civil, forzada por la muerte del dictador, y consistió sustancialmente en la traslación a la política de los valores existenciales de una sociedad, para la que la realidad de cada día y no los principios ideológicos marcaban el campo operativo a respetar. La Transición fue un fenómeno social, no previsto desde la política, y que cogió desprevenida a nuestra intelligentzia y a las fuerzas que desde el exilio pretendían restablecer la legitimidad republicana. Aquellos que no entendieron o no asumieron el nuevo rumbo de la época, desaparecieron y su lugar fue ocupado por hombres nuevos, movidos por aspiraciones sociales postmodernas y no por postulados ideológicos. Lo que en la España de 1975 llevaba a la democracia era la creencia de la inmensa mayoría de la sociedad en que la vía constitucional resultaba la única alternativa disponible digna de ser emprendida, y no una adhesión militante y activa en los valores de la política constitucional. Se trataba de una aceptación social de la democracia como forma política y en ningún caso de una auténtica inmersión en la cultura democrática constitucional.

3. Como consecuencia de todo ello, la democracia se construyó en España a resultas de la acción de un Poder constituyente evolutivo (Luhmann 1990) que, en cuestión de pocos meses, fue aflorando los textos jurídicos que acabarían dando vida al nuevo orden político, empezando por un régimen electoral limpio y altamente creíble, después del que inmediatamente se precipitó todo. La Constitución de 1978 no procede por tanto de un pacto constituyente ente franquistas y antifranquistas, sino del acuerdo interno fraguado en el seno de una sociedad que rápidamente otorgó su resuelta aquiescencia a una serie de 
hitos fuertemente consensuados que se transformaron en hechos constituyentes y a través de los que, en terminología de Gomes Canotilho (2003), cabe decir que se enunció y no se creó o dictó - según la vieja fórmula constituyente recurrente de la modernidad- un texto que en sus principios y reglas esenciales había sido ya básicamente establecido con anterioridad a su escritura expresa por las Cortes elegidas el 15 de junio de 1977. En ese mismo texto convivían potencialmente dos concepciones diferentes del derecho. Una que respondía a la idea de normatividad dirigente y a la obligatoriedad transformadora y exigente de la modernidad normativa; otra que entendía el derecho como factor de conducción de la complejidad social característico del mundo postmoderno, y se centraba en su capacidad de reconducir a la unidad y a la publicidad, una abigarrada pluralidad de fenómenos sociales que podían ser ordenados, pero no negados ni evitados. En suma, una visión de la Constitución, pero sobre todo del derecho, que no se correspondía exactamente con la expresada en el célebre ensayo de Konrad Hesse -traducido al español en 1992- tantas veces señalado como fuente de inspiración de nuestra norma fundamental: La fuerza normativa de la Constitución (1959).

\section{El significado de la Guerra y la posguerra en el ciclo constitucional español}

Contrariamente a lo que pudieran apuntar los primeros indicios, el fracaso del golpe de Estado antirrepublicano del 18 de julio de 1936 terminaría desencadenando la convulsión más destructiva en la historia de la España moderna. Y es que la incapacidad del ejército regular para adueñarse rápidamente de la situación, y el éxito relativo de las fuerzas sindicales para frenarlo en las calles, abrieron paso a la Guerra Civil y pusieron sobre el tablero del conflicto al único cuerpo militar moderno y profesional de que disponía España en aquel momento, el ejército de África. Dos monografías recientes han señalado con enorme sagacidad lo que implicaba la naturaleza colonial de semejante corporación militar [Gustau Nerín (2005) y Daniel Macías Fernández (2019)]. Más adelante extraeremos alguna otra consecuencia al respecto. Pero por el momento lo único que interesa recordar es que la revolución que siguió a la derrota del ejército en Barcelona, Madrid y, en general, todas las grandes ciudades pulverizó una sociedad a la que la guerra de conquista emprendida por las tropas africanistas que vino a continuación volvió a dar una vez más la vuelta, operando como una profunda doble-revolución que liquidó todo lo que de precedente restaba en la vida política y la sociedad española, tanto cuantitativa como cualitativamente.

Nada tiene de extraño pues, tal y como afirma Nicolás Ramiro en su 
celebrado "delantal", que "para los profesores de formación ante-bélica, pero reincorporados a la actividad universitaria, la guerra civil española [fu]era menos un acontecimiento político que un cataclismo geológico, según el tenor literal del sentido etimológico original del $\kappa \alpha \tau \alpha \kappa \lambda \nu \sigma \mu o ́ \varsigma$ griego (inundación; diluvio)" (Nicolás Ramiro 1974). La referencia es aguda y coincide incluso con el calificativo que utilizaría contemporáneamente don Manuel Azaña, durante su último viaje a Madrid en 1937, e invita a extraer dos reflexiones paralelas. Primera, que los desastres de la guerra y la ulterior demolición de lo que existía previamente, efectuada de manera minuciosa y sistemática por Francisco Franco, habían permitido reconstruir la sociedad española sobre unos cimientos diferentes y apolíticos que si bien fueron asumidos de manera silenciosa en la dura postguerra, en 1975 subsistían gracias a una camisa de fuerza y no a la estabilidad que brota de manera espontánea de la ausencia de coacción; la paz social del régimen carecía del requisito ineludible que podía hacerla definitiva: operar en circunstancias de normalidad, lo que en los tiempos que corrían equivalía a decir en condiciones de autogobierno. Segundo, la vida y la política española posterior a 1939 iban a ser reconstruidas o, si se prefiere, replantadas desde raíces nuevas, esto es, sobre fundamentos que no tenían puntos sustanciales de continuidad genealógica con los supuestos vigentes anteriores a la guerra civil, ni en la sociedad ni en la política, ni en el Estado ni en las creencias, ni en la izquierda ni en la derecha. Y esto terminaría resultando determinante, entre otras cosas, para entender qué movería a los protagonistas del proceso de transición política a actuar desde la realidad de los hechos y no desde una memoria de la que no eran herederos y, en consecuencia, a la que no se sentían vinculados.

Quienes hayan ojeado las narraciones que evocan la vida de postguerra -lo que desde una perspectiva universitaria y académica consiguen de manera conmovedora las memorias de Carlos Castilla del Pino-, pueden advertir las dimensiones de la brecha que separaba a la España de 1936 de la España de 1975. Se trata de algo que entendió muy bien uno de los más clarividentes literatos que se habían visto forzados a dejar España en 1939, Max Aub. Sus corrosivos dietarios de recuerdos, convertidos más tarde en la elocuente Gallina ciega, son el amargo testimonio de quien constata un dato para muchos desolador: en 1969 la España de Franco no tenía continuidad histórica con la España anterior al conflicto. Aquella España no existía ya en tierra española. La mayoría de sus partidarios habían muerto o abandonado el país, vencidos tras la derrota militar de la República. Y los que conservaron la vida habían capitulado psíquica y moralmente víctimas de la implacable depuración (palabra de moda en la época) que dirigía un militar africanista fogueado en la batalla, dispuesto a llevar hasta las últimas consecuencias el principio señalado por Clausewitz como fin y propósito último de la guerra: derrotar al enemigo y eliminar para 
siempre su capacidad de resistencia, suprimiendo hasta el menor atisbo de deseo de retomar las armas. Y, poco más o menos, lo mismo sucedía en los demás ámbitos, porque en la España que desfilaba ante los ojos de los que iban saliendo de las cárceles, en la que todavía se conservaba cierto espíritu de resistencia, todo era ajeno a la política y todo había sido recreado de nuevo (Mariano Rawicz 1997).

En esto estribaba -y es el razonamiento que inspira este trabajo- el supuesto característico fundamental que impulsará el proceso de reconstrucción social y política iniciado en España tras la contienda. Como en el Leviathan de Hobbes, el Estado Español había partido de cero en 1939, había nacido de una sociedad reducida a cenizas por la espada hasta un estadio o punto primario $u$ original que carecía de precedentes y en el que los hombres anhelaban como único derecho la paz. Franco era el protagonista de una redefinición artificial de la sociedad y de los españoles de enormes consecuencias. Primero, arrasando a conciencia todo lo que venía de atrás y muy especialmente el legado republicano y laico que, siguiendo la tradición de la III República Francesa, introdujeran durante la Restauración los intelectuales, y que en el siglo XX había sido el fundamento de la democracia política en las sociedades europeas. Después, inyectando valores y objetivos no necesariamente consonantes con las ideas conservadoras de la preguerra: despolitización radical, dominio de la iglesia en ciertos ámbitos privados pero no clericalismo, armonía de clases y defensa de la mass media, búsqueda individual de la prosperidad, insolidaridad en la riqueza, exaltación del ideario nacional, meritocracia, jerarquía, bienestar, consumo... que vendrían acompañados de la refundación del aparato de un Estado trazado a cartabón y escuadra por la áspera mano de un militar bragado que supo mezclar astutamente en provecho propio dosis de autoritarismo con juridicidad, derecho civil y administrativo con la ilimitada exaltación de su autoridad.

Empero, es sabido que una sociedad hobbesiana reposa en el miedo, camina en la legalidad por miedo, se encuentra impulsada por el terror reverencial que le produce el miedo a la guerra; y por eso el punto débil de aquel status quo era un miedo que consciente o inconscientemente respiraban contagiados todos los españoles. Por el contrario, el punto fuerte de aquel sistema que operaba como factor amalgamador positivo de la sociedad despolitizada de posguerra era la prosperidad económica, el bienestar del que desde finales de los cincuenta habían empezado a participar los españoles en su reconstruida vida colectiva. Una sociedad despolitizada y centrada en la mejora económica de cada uno de sus miembros comenzó a sentirse de nuevo insegura cuando, primero los ecos de la revolución portuguesa y luego los efectos iniciales de la crisis económica que sucedió a la subida del petróleo vinculado a la Guerra del Yom Kippur, cayeron sobe ella, planteando abruptamente la relación de absoluta derelicción 
política en que se encontraba la sociedad española respecto de su anciano fundador, el general Franco.

\section{El franquismo como poder de facto y sus implicaciones póstumas en una sociedad sin política}

Resulta altamente desvelador que el ejemplo que empleara Karl Loewenstein para contraponerlo a aquello que él mismo definió como Democracia Militante, en un trabajo publicado en 1937, fuera la España de Franco (Militant Democracy and Fundamental Rights). Y es que el franquismo fue durante toda su existencia un régimen de facto que sólo se interesó por su legitimidad como un a posteriori, es decir cuando se preocupó por asegurar su propia continuidad una vez hubiera muerto su fundador y principal sostén hasta 1975. Dicho de otro modo, el ejército que ganó la guerra y que tenía en Franco su líder natural procedió a amparar una reconstrucción estructural de la vida española en la que la sociedad se vería privada por completo de elementos políticos y todo quedaba reducido a un simple vivir existencial sin el afán de compartir las decisiones de gobierno, ni de transformar la realidad colectiva. Los españoles operaban en la vida social pero no podían cuestionarla. Todo lo que revestía alguna forma de ser político había sido abandonado y quedaba reservado en exclusiva al jefe del ejército vencedor que conservaba en sus manos la facultad de hacer derecho, las llamadas leyes de prerrogativa, de las que hizo uso demostrativo en su última etapa, cuando ya había comenzado la fase de institucionalización pensada para dar cierta continuidad a un régimen que -conviene insistir en ello-, mientras duró, no se había interesado nunca en justificar su poder.

Se mire por donde se mire, el franquismo fue un régimen que resultó de una derelicción política absoluta, de una despolitización completa operada por una sociedad totalmente reconstruida desde la guerra y después de la contienda, al margen de cualquier supuesto político y que no conocía la necesidad de legitimar el poder por la sencilla razón de que no era políticamente activa. Porque entre los dones que le habían sido otorgados para su uso social por el vencedor no se contaba la facultad de adherirse a una u otra forma de gobierno, sino que se le exigía simplemente una sumisión incondicional al régimen existente que se había erigido independientemente y al margen de cualquier pronunciamiento de su parte. No es lo mismo aceptación que sumisión. La primera tiene un componente activo por mucho que se manifieste pasivamente, la segunda no. La primera participa de la política, aunque sea para adherirse, la segunda no. La primera comporta una cierta forma de legitimidad, la segunda desconoce la categoría de legitimidad. 
Se trata de una situación que se ha dado muy pocas veces en la historia moderna y que permite diferenciar claramente al franquismo de otras formas o tipos de organización política coetáneas, y pretendidamente asimilables, como el fascismo, el nacionalsocialismo o incluso el régimen salazarista, fuertemente marcadas por valores ideológicos. En el franquismo, el duende de la política había abandonado la ciudad. La sociedad vivía ajena a la política porque un ejército colonial la había conquistado como si fuera terreno enemigo, reservándose el derecho a rehacerlo todo de nuevo y a su antojo. Caso único en la historia europea, la fuerza militar destinada a conquistar las colonias se vuelve contra la metrópoli y la conquista, imponiendo completamente su ley. La ley del vencedor y de su general en jefe. Mientras vivió, Franco fue poder de facto y no de iure, por mucho que en ocasiones aparentara lo contrario a través de una retórica y unas instituciones pensadas exclusivamente a efectos propagandísticos.

Muchas son las consecuencias que se pueden derivar de esta afirmación, pero a nuestros efectos interesa sólo una: la sociedad española de 1975 carecía de cualquier apego a la política y reclamaba de esta únicamente su continuidad como tal. Estaba dispuesta a adherirse al régimen que le depara la seguridad de sus goces privados, en los que situaba la suma de su interés y ambición humana. En ese sentido España era ya una sociedad posmoderna ajena por completo al concepto de clase social y de conciencia ideológica que había caracterizado al mundo burgués. Incluso de manera bastante más pronunciada que las vecinas sociedades europeas de las que procedía en parte su prosperidad. La apisonadora del franquismo había actuado a fondo, forzando al abandono de cualquier comportamiento que encerrara pretensiones cívicas. En semejante contexto había arraigado fuertemente una cultura política despolitizada, para la que los valores de la existencia cotidiana ocupaban el lugar otrora reservado a los planteamientos ideológicos de la política. Se trataba de una cultura posmoderna en la que lo que interesaba únicamente era lo que atañía a las realidades de la satisfacción económica, el dinero, el ocio, la movilidad social, el disfrute y las necesidades de los sentidos. Una cultura de sentimientos, de imágenes, de intereses fugaces y banales que renegaba de lo ontológico y lo sustancial, y centrada sólo en los fenómenos del presente. Una cultura en la que los proyectos de transformación colectiva no contaban y a la que lo que le angustiaba estaba centrado en la realidad del hoy. Esa conciencia compartida por los españoles compaginaba mal con la implicación política que exigía la democracia política. No cabía en el español de 1975 la relación de identidad entre el ciudadano engagé (comprometido) con la política que había fundado la democracia en la Italia partigiana o la Alemania antifascista. En España bastaba con una simple adhesión a la autoridad que más y mejor pudiera acreditar la satisfacción de las exigencias provenientes del mundo social. 
Conviene dejar muy claro lo que se pretende afirmar. La sociedad española de 1975 era en términos políticos, una masa informe, un cuerpo sin alma colectiva que prestaba acatamiento a un poder de hecho que no procedía de ella y que además de haberla reconstruido, la sostenía en su estado de ausencia cívica. La muerte física del dictador suponía un hecho fundamental frente al que cabían varias opciones, sustancialmente dos. Asumir un protagonismo político e implicarse democráticamente en el autogobierno colectivo o intentar que las cosas continuaran realmente como estaban, forzando la evolución hacía una democracia Constitucional percibida como un beneficio social y no como un compromiso político. Ni que decir tiene que esa fue la opción escogida, porque además de ser la más coherente con la cultura política española de la época, resultaba ser también la que se empezaba a imponer en Europa a consecuencia del nuevo tiempo histórico que la posmodernidad traía consigo. La continuidad del franquismo nunca fue una posibilidad real a tener en cuenta, porque el franquismo no era ninguna opción política, sino una situación de facto basada en la existencia física de un hombre que había muerto y que representaba la concepción castrense de unos militares africanistas que también habían desaparecido. Algún testimonio recogido en la época (véase un fragmento del Documental "Informe general", de Pere Portabella, en https://youtu.be/r4LzXO$\underline{\mathrm{n} 8 \mathrm{sY}}$ ), atestigua fielmente esa circunstancia que, de otra parte, permite explicar también que aquellos personajes y fuerzas que entendieron la atmósfera social que se respiraba fueran capaces de publicitar y simbolizar lo que suponía el triunfo político de aquel medioambiente social despolitizado que impregnaba el ser colectivo español. En todo caso, importa subrayar que la Constitución advino en España sin que se impusiera previamente una cultura política cívica altamente ideologizada. La democracia llegó por la adhesión indolente de una sociedad no comprometida con la política, en la que el franquismo no había dejado ningún vestigio (ni siquiera la Monarquía, véase al respecto, Eloy García, El significado intelectual del rey en la monarquía parlamentaria, Madrid 2021) y se fundamentó en una legitimidad que tuvo bastante de aceptación pasiva y casi nada de entusiasmo militante. Lo que explica que en cuanto empezaron a rodar normalmente las cosas en la existencia constitucional española, el interés por los asuntos políticos quedó reducido a un juego institucional en el que había mucho de representación y muy poco de un activismo que había quedado reservado casi exclusivamente a la promoción de unos intereses sociales y económicos que con la globalización habían situado finalmente a España en el mercado mundial. 


\section{La Constitución enunciada por el Poder Constituyente evolutivo y el desfallecimiento de la fuerza normativa del derecho}

No hace al caso repetir aquí consideraciones que se han expuesto ya en otros trabajos anteriores; sí interesa insistir sin embargo en el dato de que la Constitución Española de 1978 había sido enunciada ya en buena medida en julio de 1977, cuando se reunieron las Cortes que procederían a redactarla. Significativamente no se habla de Poder constituyente cuando se alude a este episodio. Y es que el proceso de elaboración de la actual Constitución española responde a otro tipo categorial que, utilizando categorías de Luhmann, hemos venido a llamar Poder Constituyente evolutivo. Un proceso público en el que la sociedad impone a la política y al derecho un punto de equilibrio en el que confluyen los complejos intereses y factores que la mueven, y en el que la voluntad explícita de los hombres cuenta menos que la adecuación y la coherencia entre atmosfera social y estructura normativa. La Constitución es en esta situación un punto de encuentro que permite articular un punto de referencia común donde se conectan y comunican diferentes sistemas. Su función consiste más en dar conocimiento general de donde se encuentran situados los equilibrios y cuáles son los factores que operan en la realidad y en cómo pueden ser conducidos, que en imponerse a ellos. En cierto modo el constitucionalismo posmoderno arranca de una doble renuncia, a dominar la marcha de los acontecimientos y a sobreponerse a los hechos. Y en cierto sentido supone una claudicación respecto de la idea de normatividad dirigente. Pero es el derecho quien claudica y con él la Constitución normativa.

En este sentido es importante resaltar que no estamos ante una vuelta a las posiciones doctrinales del siglo pasado que negaban la fuerza normativa del derecho, sino ante la constatación de un dato incontrovertible: la realidad de los hechos es más compleja y profunda que la capacidad de los hombres de entenderlos y de crear artificios culturales para dominarlos. Podemos aspirar a conducirlos, no a imponerles una dirección transformadora que haga de ellos algo diferente de lo que en realidad son. Pero no se trata de sostener que la Constitución española de 1978 se construye en esa idea de normatividad, sino tan sólo de advertir que junto con la idea de Constitución dirigente que recogen muchos, la mayoría, de sus preceptos, existen también otros que responden a la nueva realidad posmoderna construida desde una renuncia a la imperatividad y al mandato en favor de un señalamiento de vías y opciones que quedan al albur de los actores políticos. Tal es el caso, por ejemplo, de lo que sucede con bastantes de los preceptos relativos al Estado Autonómico y a sus desarrollos potenciales. Pero no se trata tanto de señalar un sector en que la debilidad del derecho como fenómeno normativo pueda ser más acusado, cuanto de recordar que la atmósfera en que se crea, aplica e interpreta el derecho en este siglo XXI 
no participa de la idea de la eficacia social de lo jurídico. Este relativismo se aprecia en nuestra Constitución más que en otros textos constitucionales de la generación anterior.

Empero, no se trata sólo del desfallecimiento de la fuerza normativa del derecho; otros fenómenos similares, que afectan a las categorías y a los conceptos construidos por la modernidad, están socavando actualmente la capacidad de la Constitución de imponer un camino a la política y de hacer operativa la democracia. El problema está situado en dos polos; uno, la ausencia de implicación política de un ciudadano que quiere ser el individuo que se beneficia de su existencia social, sin ofrecer nada a cambio y sin admitir limitaciones en su posición de autodeterminación jurídica. Otro, en el entendimiento cultural de la política como una realidad ajena y en la que se debe participar únicamente si se pueden obtener posiciones de poder susceptibles de beneficio particular. No es que en el marco de la Constitución española el problema se sienta de forma diferente al resto de las Constituciones europeas. Es que, habiendo llegado antes y más profundamente a una democracia sin política, los españoles estamos más inermes ante un mundo individualizado y fragmentado en el que el hombre solo es siempre un hombre desarmado. Urge pues recuperar la política, como también urge admitir las limitaciones de una normatividad que debe adaptarse a una misión más modesta: la de conducir el mundo y no dirigirlo.

\section{Bibliografía:}

Blühdorn, I., La democracia simulativa. Nueva política tras el giro posdemocrático, Bogotá, 2020.

García López, E., El significado intelectual del rey en la monarquía parlamentaria, Madrid 2021.

Gomes Canotilho, J. J., Direito Constitucional, 7ª. Ed., Coimbra, 2003.

Hesse, K., "Die normative Kraft der Verfassung", 1959. (Trad. al español "La fuerza normativa de la Constitución", en Escritos de Derecho Constitucional, CEC, 1992).

Loewenstein, K., "Militant Democracy and Fundamental Rights", The American Political Science Review, Vol. 31, No. 3 (Jun., 1937), pp. 417-432.

Luhmann, N., Sistema jurídico y dogmática jurídica, Madrid, 1983.

Luhmann, N., "Verfassung als evolutionäre Errungenschaft", en Rechtshistorisches Journal 9, 176-220.

Macías Fernández, D., Franco nació en África, Madrid, 2019.

Mayer, A., La persistencia del Antiguo Régimen, Madrid, 1984.

Nerín, G., La Guerra que vino de África, Barcelona, 2005.

Portabella, P., "Informe general", Documental. Fragmento disponible en https://youtu.be/ r4LzXO-n8sY

Ramiro, N., El animal ladino y otros estudios políticos, Madrid, 1974.

Rawicz, M., Confesionario de papel, Granada, 1997. 
Sánchez Agesta, L., Historia del Constitucionalismo Español, Madrid, 1955.

Shklar, J., Después de la Utopía. El declive de la fe política, Madrid, 2020.

Solé Turá, J., Constituciones y periodos constituyentes en España: (1808-1936), Madrid 1977.

Tomás Villarroya, J., Breve Historia del Constitucionalismo español, Barcelona, 1976. 